\title{
Contribution of Adult Education in Promoting Rural Development
}

\author{
Radhika Kapur* \\ Pedagogy and Organizational Culture in Nursery Schools, Delhi University, New Delhi, India \\ *Corresponding Author: Radhika Kapur, Pedagogy and Organizational Culture in Nursery Schools, Delhi University, New Delhi, India.
}

Received: July 15, 2019; Published: August 12, 2019

DOI: 10.31080/ASAG.2019.03.0610

\begin{abstract}
The main objective of this research paper is to understand the contribution of adult education in promoting rural development. In India, more than 70 percent of the population is residing in rural communities. In rural areas, agriculture and farming practices are regarded as the primary occupations of the individuals, but they are non-literates and are residing in the conditions of poverty and backwardness. The rural individuals have acquired efficient understanding of the fact that through the acquisition of education, individuals will be able to promote better livelihoods opportunities. In rural areas, the system of education and school structures are not in a well-developed state. There is a need to formulate measures, policies and programs to make improvements in the system of education. In addition, there have been establishment of adult education centres, which are rendering an effective contribution in generating interest among the rural adults to acquire education. The individuals are also generating knowledge in terms of innovative methods to enhance agricultural productivity. The main concepts that have been taken into account in this research paper include, factors that need to be up-graded in adult education to promote rural development, competencies and aptitude for rural development, and relationship between adult education and rural development.
\end{abstract}

Keywords: Adult Education; Competencies; Improvements; Measures; Rural Development

The role of adult education in facilitating social and economic progress is well-accepted and acknowledged on a comprehensive scale. Access to education is critical to generate awareness in terms of emerging opportunities that accompany economic growth. Adult education is regarded to render a significant contribution in bringing about development of the individuals and communities in various spheres. These include, social, political, economic and cultural. India has the second largest education system in the world after China. The scale of operation that is involved in promoting quality of education for all within the country is unique and challenging. At the same time, the nature of problems, affecting the system of education are diverse and deep rooted. There are several problems that are causing barriers within the course of development of the system of education. These are, lack of financial resources, lack of political will, and shortage of teachers [1].

The major role that adult education has played in leading to progression of rural communities is, it transforms individuals from the shades of social backwardness to light of social amelioration [1]. In addition, the rural individuals are able to recognize the significance of education. There have been development of adult education centres in rural communities. The adults, who have not been enrolled in schools before or have dropped out prematurely are provided with the opportunities to hone their literacy skills. Agriculture is the major occupation of the individuals in rural communities. There have been establishment of training centres in rural communities, which are providing information to the agricultural labourers in terms of utilization of modern, scientific and innovative methods to enhance productivity. Through acquisition of education, the individuals and communities are able to bring about improvements in their overall quality of lives. Hence, adult education has rendered an indispensable contribution in promoting the development of individuals and communities in rural areas.

Factors that need to be Up-graded in Adult Education to Promote Rural Development

In order to promote up-gradation of adult education in rural areas, there are certain factors, which need to be taken into consideration:

- Teaching-Learning Methods: The utilization of teachinglearning methods have to be in accordance to the needs and requirements of the students, academic subjects and academic goals. In rural educational institutions, technology has not been used to a much greater extent as compared to educational institutions in urban areas. The teaching-learning methods are traditional. When the instructors are imparting knowledge to the adult learners in terms of academic subjects, they need to ensure, they are able to understand the concepts satisfactorily. It is vital to make use of technologies and other innovative methods in order to promote effectual 
student learning. In particularly rural areas, it is essential to make use of technologies and scientific teaching-learning methods.

- Size of the Schools: Rural schools are smaller in size as compared to the other schools because of the sparse population of the community and the choice of the community. Rural individuals make selection of smaller schools, because their common sense confirms that schools are the most effectual places, where individuals can receive education. Furthermore, they are also able to understand the ways that are necessary to bring about improvements in the overall quality of lives. Overwhelming education research has found many advantages of smaller schools over larger schools, including better achievement, higher graduation rates, fewer discipline problems and higher rates of participation in extra-curricular activities [2]

- Transportation: The lack of transportation facilities are regarded as the major barriers within the course of acquisition of education. The lack of transportation affects all other issues facing rural schools and deepens their severity. In many rural communities, there is not any availability of public transportation. Hence, due to this, individuals find difficult to commute to schools. It is necessary to bring about improvements in roads, transportation and infrastructural facilities. When there will be availability of transportation facilities, whether personal or public, then the individuals will not experience any problems in transferring to schools. Research has indicated, due to availability of appropriate transportation, even secondary and higher secondary school students develop the confidence to travel on their own [2].

- Social Service, Infrastructure, and Philanthropic Support: In rural communities, the individuals are residing in the conditions of poverty and backwardness. There is deficiency in terms of three aspects of social service, infrastructure and philanthropic support. These aspects are regarded important in supporting education. Rural communities also do not have philanthropic institutions that many urban and sub-urban communities rely on to supplement the cost of education [2]. The individuals, who are residing in the conditions of poverty normally experience problems in financing their education. Hence, it is necessary to make provision of financial assistance. In some rural schools, education is provided free of cost, but students need to meet the expenses related to other aspects, such as, school bags, stationary, transportation and so forth.

- Use of Technology: The use of technology is regarded as one of the significant aspects in enhancing learning and augmenting ones understanding in terms of various concepts. Through the use of technologies, the implementation of tasks and activities have become manageable and convenient. The use of internet has rendered a significant contribution in bringing about improvements in the tasks and living standards of the individuals. In order to be well-equipped with technologies, it is vital for individuals to practice it. With sufficient practice, the individuals are able to generate awareness in terms of usage of technologies. In rural schools, adult education centres and other training centres, it is necessary to promote the usage of technology.

- Qualified and Experienced Instructors: When the recruitment and selection of instructors takes place in educational institutions and training centres, it needs to be ensured, they are well-qualified and experienced. They should be wellaware of the subjects and concepts that they are imparting to the students and instructional strategies that need to be put into practice. Skilled instructors, who have high expectations for the learners and employ appropriate teaching methods are rendering an effective contribution in promoting student learning and enhancing the overall system of education. The instructors need to conduct research in terms of advancements taking place in the system of education and augment their knowledge and competencies accordingly.

- Effective School Leaders: As with the instructors, the researchers have concluded that effective and competent leaders, who support teaching and learning at high levels are regarded as indispensable in a high quality curriculum. The adults in rural areas, particularly the ones, who are 60 years of age and above are normally apprehensive. They lack the confidence and feel diffident in communicating with others. Therefore, the possession of effective leadership skills will enable the instructors to direct them appropriately. They need to guide the learners in an appropriate manner in terms of significance of education, help them in enhancing their skills and abilities and how to make use of education in enhancing their overall quality of lives.

- High Quality Curriculum: An enriched and authentic curriculum is regarded as significant in promoting rigorous academic work with value to the community of the students as a hallmark of high quality education. In order to bring about improvements in the system of education and promote student learning, it is essential to support high quality curriculum. The curriculum and the instructional systems should make provision of adequate knowledge and generate awareness in terms of various aspects that are necessary to enrich their livelihoods opportunities. A high quality curriculum is essential for satisfactory education to be provided to rural individuals with only marginally higher costs, if schools have the tools that are available to employ distance learning strategies to instruct students [2].

- Targeted Strategies for "At-Risk Students": Rural places frequently have a number of "at-risk students". At-risk students are the ones, who are residing in the conditions of poverty, backwardness, who are disabled and possess learning disabilities [2]. The rural individuals, usually belonging to various age groups, experience these problems. Therefore, in educa- 
tional institutions and training centres, it is essential to make provision of opportunities and facilities for the students that would enable them to acquire education and understanding in a well-organized manner. The at-risk students need encouragement and support from family members and instructors to acquire education and enhance their livelihoods opportunities. It is understood on a comprehensive basis that education renders a significant contribution in alleviating poverty. It is difficult to quantify the contribution of education to promote economic growth [3].

- Quality School Facilities: Safe and appropriate facilities in schools are regarded to be of utmost significance in increasing the rate of enrolment of students and even in retaining instructors and other staff members within their jobs. These are regarded as an essential part of the educational program, because researchers have noted the connection between the overall environmental conditions of the educational institutions and student learning. It is difficult for the instructors to teach and for students to learn, particularly when there are not availability of appropriate facilities. The important facilities that are required in schools are, furniture, technologies, heating and cooling equipment in accordance to the weather conditions, clean drinking water, lighting, electricity, restrooms and teaching and learning materials. The availability of these facilities would render an effective contribution in bringing about improvements in the system of education and achievement of personal and professional goals.

\section{Competencies and aptitude for rural development}

The individuals, who are participating in the formulation of measures, policies and programs to bring about rural development, need to augment their competencies and aptitude. Furthermore, the individuals, belonging to rural communities are also required to augment their knowledge and competencies to sustain their living conditions better and bring about development of rural areas. The important aspects that need to be taken into account are [4].

\section{Basic skills for rural individuals}

For leading to development of rural communities, it is essential to make provision of education and skills to the individuals. As when youth will be effectively trained, they will render a significant contribution in putting into practice, their knowledge and skills to promote development of rural communities. It is necessary to make provision of education to them that would motivate them to study. In addition, there have been initiation of training programs to enhance their aptitude and opportunities to pursue higher education. The important aspects that need to be taken into account are stated as follows:

- Improving the Quality of Basic Education: The basic education is regarded to build the foundation on which learning takes place between individuals. The acquisition of basic education is regarded important in leading to effective growth and development of the individuals. Therefore, there is a need to bring about improvements in the quality of basic education. In order to bring about improvements in the quality of basic education, it is vital to focus upon number of factors. These include, making use of appropriate teaching-learning methods and instructional strategies, providing adequate infrastructure, equipment, tools and other materials that would enrich student learning, encouraging skills development and creative activities, ensuring that teachers are wellqualified and experienced and creating pleasant and amiable environmental conditions within educational institutions. These factors would lead to enrichment of the overall system of education and encourage student learning.

- Skills for Employment: Finding and maintaining of employment opportunities requires broad-based comprehensive skills and job-related skills. These skills are acquired by the individuals, either in training institutions or on-the-job. In rapidly evolving and globally competitive economy, they include, personal capabilities, such as, flexibility, resourcefulness and communication. Vocational training centres aim to enhance the skills and abilities of the individuals, so they can be well-prepared for the labour market. Apart from agriculture and farming practices, the individuals get engaged in other activities as well, such as, production of food items, artworks and handicrafts and so forth. For up-grading their skills to generate productivity, the individuals get enrolled in training centres. In rural communities, the training centres have been established that aim to make provision of skills and abilities to the individuals, so they can attain employment opportunities and carry out their job duties in a wellorganized manner.

- Higher Education: In the present existence, the individuals, belonging to rural communities have recognized the significance of education to such a major extent that they aspire to attain higher education as well. Acquisition of higher education is regarded to be of utmost significance in developing ones knowledge, competencies and aptitude. In rural communities, the system of higher education is not in a well-developed state, hence, the individuals migrate to urban areas to get enrolled in higher educational institutions. Acquisition of higher education is usually challenging for individuals, belonging to rural communities. They are required to manage other responsibilities as well, such as, housing accommodation, transportation, studies and other expenses. The management of these responsibilities become severe, when individuals experience financial problems. Hence, they are required to get engaged in full-time or part-time jobs or attain scholarships. Upon completion of their academic programs, they either return to their homes or continue to stay in urban areas and seek employment opportunities. 


\section{- Education and Skills Development for School Drop-outs:} The rural individuals usually drop out of schools prematurely. There are number of factors, which lead to their drop-out. These include, financial problems, distance of schools from homes, inappropriate teaching-learning methods, inadequate teaching-learning materials, lack of infrastructure and civic amenities, shortage of teachers, discriminatory treatment against girls, occurrence of criminal and violent acts, lack of creative activities and lack of interest and motivation on the part of students. One or more of these factors are the major causes that encourage students to drop-out from schools, before their educational skills are honed. When the rural individuals are unable to acquire education and skills, they experience barriers within the course of attainment of better livelihoods opportunities. Therefore, in rural communities, it is necessary for the individuals to get enrolled in educational institutions and training centres to acquire knowledge and enhance their skills, so they can sustain their living conditions better.

- Skills to Operate in Markets: It has been stated above that apart from getting engaged in agriculture and farming practices, the rural individuals participate in other areas as well to generate a source of income to sustain their living. These include production of food items, artworks, handicrafts, and so forth. When they attain the skills to get engaged in production of various items, they need to generate awareness in terms of labour market factors. Individuals need skills and competencies to operate in the open and demanding markets. Through advancements taking place and the utilization of modern, scientific and innovative methods, it is essential to make use of these to enhance productivity. They need more and better market information and greater understanding of the costs and revenues [4].

- Participation in Various Activities and Functions: The participation of the rural individuals is encouraged in social, political, economic, cultural and religious activities. In rural communities, in some cases, women and girls are not encouraged to acquire education or participate in any tasks and activities. They are required to remain confined within the house and manage the household responsibilities. Through adult education, individuals are generated awareness that it is essential for them to participate in various activities and functions. This applies mainly to women and girls. When they will participate in these functions, they would not only develop communication skills, confidence and interactive abilities, but they would also generate awareness in terms of various aspects, which are crucial in bringing about improvements in their living standards.

- Accessibility to Knowledge Resources: In rural communities, apart from the establishment of adult education and training centres, it is vital to promote accessibility to knowledge resources. The various resources that may enhance the knowledge among individuals are libraries and computer centres. The libraries should be established, with variety of reading materials, such as, books, articles, newspapers, magazines, reports and so forth. Within libraries, there are organization of speeches as well, which are normally attended by the individuals, so they can attain good knowledge. Computer centres are the ones, which have certain number of desktop computers, and other technologies, such as, scanners and printers. When individuals are required to carry out their tasks, they make visits to computer centres, especially when they do not possess technologies at home. Therefore, accessibility to knowledge resources is crucial in development of competencies and aptitude.

- Implementing Measures and Programs: The programs and measures are formulated by the individuals in leadership positions, who have the main objective of promoting rural development. In rural India, there are number of aspects, which need to be improved. These include, the system of education, medical and health care facilities, agricultural sector and farming practices, industries, living conditions of individuals, infrastructural facilities, roads and transportation, technologies, and overall environmental conditions. Furthermore, the measures need to get initiated to eliminate the problems of poverty, illiteracy, unemployment and homelessness that are imposing unfavourable effects upon the lives of the individuals. In implementation of measures and programs, it needs to be ensured that they prove to be beneficial to the individuals. The rural individuals are able to upgrade their overall quality of lives through various measures and programs.

- Conducting Research and Analysis: Research and analysis are regarded as important aspects, which generate information among individuals regarding the areas, which need to be improved. In rural communities, there are large number of individuals and families, who are residing in the conditions of poverty and backwardness. They have their own cultures, practice their own customs and have their own viewpoints and perspectives. It is vital to conduct research and analysis and implement measures to bring about improvements. The efforts need to be made to revitalize agricultural education. This is focused upon because agriculture is the main occupation of the individuals. It should concentrate on upgrading of curriculum and instructional systems, transformation in the teaching practices and increasing the enrolment of individuals in educational institutions and training centres.

- Making use of Technologies: In rural communities, it is essential to generate information among individuals in terms of usage of technologies. The utilization of technologies have played an important part in enriching the lives of the individuals. The rural youth are making use of computers and mobile technologies to acquire education and augment their understanding in terms of various areas. Whereas, elderly individuals usually make use of them for leisure and recreational purposes. There- 
fore, it can be stated that there are multiple uses of technologies. They are used to communicate, generate information in terms of various areas, search for employment opportunities, identification of educational institutions and training centres, making purchases and sales of various items and recreational purposes. The usage of technologies by rural individuals have led to improvements in their living conditions to a major extent.

\section{Relationship between adult education and rural development}

There is a strong relationship between adult education and rural development. Through adult education, the individuals are generating information in terms of various aspects, which are necessary to bring about improvements in their overall quality of lives. The development of agricultural sector in rural areas is regarded as the major component of the successful rural development program, as 70 percent of the population in India is employed in this sector. The relationship between the two concepts needs to be viewed within the framework of far-reaching transformations in the social and economic sectors, institutions and procedures. These need to be viewed in terms of the balanced economic and social development with emphasis put on the equitable distribution, as well as the rapid generation of the benefits of higher level of living [5]. Through adult education, the individuals are able to enrich their understanding in terms of the factors that would be productive in enriching their living conditions.

Among the comprehensive goals, there are generation of skills development programs and employment opportunities for rural individuals. These individuals are augmenting their knowledge and competencies in terms of utilization of technologies, and modern, scientific and innovative methods in increasing productivity. Through acquisition of education and development of skills, the individuals are able to enhance their understanding in terms of health care and well-being, child development, diet and nutrition, management of household responsibilities, work ethics, effective communication and so forth. In the present existence, there has been an increase in the number of rural individuals, who are migrating from rural to urban communities to enhance their livelihoods opportunities.

The educational needs of rural individuals are classified into four main categories [5].

- Basic Literacy Skills: The basic literacy skills of reading, writing and numeracy are regarded to be of utmost significance. The individuals need to acquire these skills to carry out daily routine activities. For instance, when they are purchasing goods from the market or need to transfer from one place to another, they need to possess the basic literacy skills.

- Education for Family Improvement: It is vital to possess adequate knowledge to bring about improvements within the family. In order to manage the household responsibilities and carry out upbringing of the family, the individuals need to generate awareness in terms of number of factors. These include, implementation of household chores, such as, cleaning, washing, preparation of meals, fetching water, rearing of livestock and so forth. Apart from these, one has to carry out the function of child development appropriately, manage health care and well-being, financial resources and maintain good terms and relationships with each other.

- Community Improvement Education: Community improvement education is the education that is designed to strengthen local and national institutions and processes through instruction. The rural individuals need to generate awareness in terms of various aspects, such as, local and national government, co-operatives and community projects. Furthermore, the rural individuals are dependent upon the natural environmental conditions to carry out various tasks and activities. For instance, they obtain water from the water bodies. Therefore, it is necessary to make them aware in terms of preservation of the environment, keeping the water bodies clean and eliminating all forms of pollution.

- Occupational Education: Occupational education is designed to develop knowledge and skills associated with various economic activities that are useful in making a living. The main objective of rural individuals is to generate a source of income. Research has indicated that individuals, residing in the conditions of poverty, who struggle to make ends meet, even send their children to urban areas to work as domestic helps. From the stage of early childhood, the children are trained in terms of implementation of household responsibilities and taking care of needs and requirements of family members. Hence, they are in some cases fortunate enough to migrate to urban households, where they work as domestic helps. In return they are provided with education, money and other benefits, which would lead to improvements in their overall quality of lives.

Therefore, it can be stated that through adult education, individuals are generating information in terms of these aspects. Research has indicated that rural individuals give more preference to acquisition of employment opportunities, rather than education. But through adult education, they are able to recognize the significance of education and form the viewpoint that how important and meaningful it can be in enriching their lives. Effective and welldesigned educational programs catering to various academic concepts are needed, if education is to render an effective contribution in promoting rural development [5].

\section{Conclusion}

Adult education renders a significant contribution in promoting rural development. It is vital for the individuals to conduct an analysis of the areas that need to be improved and put into operation the measures and strategies to bring about improvements. In order to promote up-gradation of adult education in rural areas, the 
various factors are, teaching-learning methods, size of the schools, transportation, social service, infrastructure, and philanthropic support, use of technology, qualified and experienced instructors, effective school leaders, high quality curriculum, targeted strategies for "at-risk students" and quality school facilities. Apart from acquisition of education and generating awareness in terms of various aspects, it is necessary to augment ones competencies and aptitude. These are, improving the quality of basic education, skills for employment, higher education, education and skills development for school drop-outs, skills to operate in markets, participation in various activities and functions, accessibility to knowledge resources, implementing measures and programs, conducting research and analysis and making use of technologies. When the rural individuals will generate awareness and implement these aspects, they would be able to enhance knowledge, competencies and aptitude.

There is a strong relationship between rural development and adult education. The educational needs of the adult individuals are classified into four aspects. These are, basic literacy skills, education for family improvement, community improvement education and occupational education. When the adults get enrolled in educational institutions or training centres to acquire education, emphasis is put upon these four aspects. When they are able to enhance their skills in terms of these four aspects, they are able to bring about improvements in the overall quality of lives and achieve personal and professional goals. Therefore, it can be stated that it is vital to formulate measures and programs that are necessary to augment the system of education in rural areas and generate awareness among individuals in terms of significance of education.

\section{Bibliography}

1. Rural Education. Kurukshetra 59.7 (2011): 1-50.

2. Malhoit GC. "Providing Rural Students with a High Quality Education: The Rural Perspective on the Concept of Educational Adequacy". Rural School and Community Trust (2005).

3. Atchoarena D and Sedel C. (n.d.). Education and Rural Development: Setting the Framework.

4. Education and Skills for Rural Development. (n.d.).

5. Education and Development. (n.d.).

\section{Volume 3 Issue 9 September 2019}

(C) All rights are reserved by Radhika Kapur. 